\title{
Geração de metano a partir de resíduos lignocelulósicos oriundos da produção do biocombustível: revisão
}

\author{
Methane generation from lignocellulosic waste \\ of the biofuel production: a review
}

Adriana Guimarães Costa | Francisca Gleyciara Cavalcante Pinheiro | Gleycielle Cavalcante Pinheiro André Bezerra dos Santos | Sandra Tédde Santaella | Renato Carrhá Leitão

Data de entrada: 28/02/2013 | Data de aprovação: 06/06/2013

DOI: http://dx.doi.org/10.4322/dae.2014.003

Resumo

O Brasil gera uma grande quantidade de resíduos lignocelulósicos provenientes das cadeias produtivas dos biocombustíveis, que podem ser aproveitados para produção de combustíveis de segunda geração como, por exemplo, o metano. No entanto, o aproveitamento desta biomassa como fonte de energia pela via fermentativa normalmente requer pré-tratamento do material lignocelulósico, visando solubilização de açúcares ou remoção de lignina, que será definido em função da característica do substrato utilizado ou da posterior utilização do hidrolisado. A escolha deve ainda considerar aspectos operacionais, custos e geração de substâncias tóxicas.

Palavras-chave: Energia renovável, biomassa lignocelulósica, biogás, pré-tratamento.

Abstract

Brazil generates a lot of waste from lignocellulosic biofuel production chains, which can be exploited for the production of second generation biofuels such as methane. However, the use of this biomass as energy source via fermentation usually requires pre-treatment of the lignocellulosic material in order to solubilise the sugars or to extract the lignin. The pre-treatment process will be defined as a function of the characteristic of the substrate used or the subsequent use of the hydrolysate. The choice should also consider operational aspects, cost and generation toxic substances.

Key-words: Biofuels, lignocellulosic biomass, methane.

Adriana Guimarães Costa*

Eng. Sanitarista (UFPA), Mestre em Saneamento Ambiental (UFPB), Doutora em Saneamento Ambiental (DEHA/UFC) e Docente do Instituto Federal de Educação Ciência e Tecnologia do Ceará. Coordenadora do Curso de Tecnologia em Gestão Ambiental (IFCE). Francisca Gleyciara Cavalcante Pinheiro

Tecnóloga em Processos Químicos e Mestranda no Programa de Pós-graduação do Centro de Ciências. Departamento de Química Orgânica e Inorgânica. Universidade Federal do Ceará.

Gleycielle Cavalcante Pinheiro

Graduanda em Tecnologia e Gestão Ambiental do Instituto Federal de Educação Ciência e Tecnologia do Ceará.

André Bezerra dos Santos

Engenheiro Civil, PhD, Wageningen University, Holanda. Professor Adjunto-Departamento de Engenharia Hidráulica e Ambiental da Universidade Federal do Ceará. Coordenador do Laboratório de Saneamento, LABOSAN-DEHA-UFC

Sandra Tédde Santaella

Química, Doutora em Engenharia Civil. Professora Associada da Universidade Federal do Ceará, lotada no Instituto de Ciências do Mar (LABOMAR), professora do Curso de Pós-graduação em Ecologia e Recursos Naturais da UFC e colaboradora do Programa de Pós-graduação em Hidráulica e Saneamento da Escola de Engenharia de São Carlos da Universidade de São Paulo e do Programa de Pós-graduação em Ciências Marinhas Tropicais (LABOMAR/UFC)

Renato Carrhá Leitão

Engenheiro Civil, PhD, Wageningen University, Holanda. Pesquisador da Embrapa Agroindústria Tropical

*Endereço para correspondência: Departamento da Área de Química e Meio Ambiente, Instituto Federal de Educação Ciência e Tecnologia do Ceará - DAQMA/IFCE. Av. Treze de Maio, 2081, Fortaleza, CE, Brasil. CEP: 60040-531.

Tel: +55(85)3307-3646

E-mail: adrianagc@ifce.edu.br 


\section{Introdução}

O desenvolvimento não baseado nos preceitos da sustentabilidade e a exploração irracional dos combustíveis fósseis, bem como a perspectiva de aumento do preço do petróleo vêm motivando esforços para desenvolver fontes alternativas de energia. Nesse contexto, os biocombustíveis, como o etanol, o biodiesel e o biogás podem ser usados para diminuir o uso de gasolina e óleo diesel e, consequentemente, minimizar os impactos ambientais.

Apesar de os biocombustíveis terem surgido como uma alternativa energética de menor impacto ambiental, os resíduos provenientes desta cadeia produtiva necessitam de destinação apropriada. Muitas são as aplicações dos resíduos (ração animal, combustível para caldeiras, polímeros, condicionador do solo, forragem para animais, fertilizante, adubo, indústria têxtil e automobilística, etc.). Entretanto, existe ainda um excedente que gera problemas ambientais e de estocagem (Sun et al., 2004). De acordo com o Plano Nacional de Energia 2030, o setor sucroalcooleiro brasileiro é o principal produtor de resíduos agroindustriais, cuja previsão do total de cana moída na safra 2012/13 é de 596,63 milhões de toneladas (Conab, 2012), com aumento de 6,5\% em relação à safra 2011/12, que foi de 560,36 milhões de toneladas, o que implica um total de 80,54 milhões de toneladas de bagaço de cana-de-açúcar, já que para cada tonelada de cana processada é gerada 0,135 ton de bagaço (Brasil, 2007). Outra cultura que vem se estabelecendo no país é a do dendê. Nos últimos anos, tem ocorrido aumento exponencial da área plantada de dendê, destinado à produção de biodiesel. Esta cadeia produtiva gera aproximadamente 78 ton de resíduo para cada 100 ton de cachos de frutos processados, dos quais têm-se: os cachos vazios, a torta de palmiste, a fibra da prensagem do mesocarpo do dendê, as cascas e efluentes (Furlan Jr., 2006). Segundo o Ministério da Agricultura, a safra de palma divulgada em agosto de 2010 foi de 1,1 milhão de toneladas, e sabendo-se que apenas $22 \%$ desse total corresponde ao óleo (Furlan Jr., 2007), tem-se um total 0,86 milhões de toneladas de resíduos. Além desses resíduos têm-se, ainda, os resíduos do processamento do algodão, da mamona, do milho e muitas outras biomassas lignocelulósicas.

Uma alternativa ambientalmente sustentável para uso destes resíduos é a geração de energia renovável via digestão anaeróbia para produção de metano. A biodegradabilidade anaeróbia dos resíduos agrícolas provenientes da cadeia produtiva do biocombustível vem sendo objeto de diversos estudos (Fernandes et al., 2009; Souza et al., 2010; Aguiar e Ferraz, 2011). Há um consenso entre os autores de que a digestão anaeróbia dos materiais lignocelulósicos é limitada pela hidrólise. Segundo Angelidaki et al. (2009), isso ocorre devido à barreira física proporcionada pela lignina e hemicelulose e pela porção cristalina da celulose. Para aumentar a biodegradabilidade e acelerar o processo de hidrólise, faz-se necessário que o material sofra primeiramente um pré-tratamento (Sun e Cheng, 2002; Taherzadeh e Karimi, 2008).

Diversos pré-tratamentos podem ser utilizados para aumentar a biodegradabilidade dos materiais lignocelulósicos (moagem, pirólise, hidrólise ácida e/ou alcalina, explosão a vapor, hidrólise enzimática, dentre outras). Cada pré-tratamento deve ter seus parâmetros operacionais estudados (tempo de reação, temperatura, pressão e concentração do catalizador) para maximização da produção de açúcares, aumento de acessibilidade ou remoção de lignina, e minimização da produção de compostos recalcitrantes ou tóxicos (Vázquez et al., 2007, Petersen et al., 2009).

\section{Digestão anaeróbia do material lignocelu- lósico}

As cadeias produtivas dos biocombustíveis geram vários resíduos, dentre eles os lignocelulósicos. Fengel e Wegener (1984) consideram que o material lignocelulósico consiste principalmente em três tipos diferentes de polímeros: celulose, hemicelulose e lignina, que são associados a outros. A celulose é um polímero formado por uma cadeia de glicose, a hemicelulose é um polímero composto por açúcares de cinco e seis carbonos e a lignina é um polímero fenólico que constitui o material estrutural da planta, associado à parede vegetal celular, responsável pela rigidez, impermeabilidade e resistência a ataques aos tecidos vegetais. A digestão anaeróbia do material lignocelulósico é limitada em virtude de sua composição e estrutura.

A rota metabólica da digestão anaeróbia é dividida basicamente em quatro etapas: Hidrólise, Acidogênese, Acetogênese e Metanogênese. Dentre estas, três grupos de microrganismos participam do processo: bactérias fermentativas, 
bactérias acetogênicas e archeas metanogênicas. $\mathrm{O}$ produto final das bactérias fermentativas (hidrolíticas e acidogênicas) será substrato para as acetogênicas, as quais por sua vez fornecerão o substrato necessário para as metanogênicas.

De uma maneira geral, na digestão anaeróbia do material lignocelulósico, a matéria orgânica sofre inicialmente hidrólise (passo limitante do processo), em que os polímeros orgânicos são decompostos em monômeros como açúcares e ácidos orgânicos por meio de enzimas. A conversão de biopolímeros é catalisada por exoenzimas (hidrolases) excretadas por bactérias facultativas ou acidogênicas anaeróbias obrigatórias (Gallert e Winter, 2005), incluindo os gêneros Clostridium, Acetivibrio, Bacteroides, Selenomonas e Ruminococcus (Insam et al., 2010).

Como cada exoenzima converte apenas um substrato ou grupo específico de substratos, diversas bactérias acidogênicas são necessárias para digerir o material lignocelulósico (Fernandes, 2010). A celulose é insolúvel e a degradação por bactérias e fungos ocorre extracelularmente por um complexo multienzimático de elevada massa molecular chamada celulase, que catalisa de forma eficiente a hidrólise da celulose (Leschine, 1995). Como exemplo pode-se citar a celulase produzida pelas bactérias dos gêneros: Clostridium, Cellulomonas, Bacillus, Termomonospora, Ruminococcus, Bacteroides Erwinea, Acetivibrio, Microbispora e Streptomyses (Sun e Cheng, 2002).

Para completa degradação da celulose, três celulases são necessárias: endoglicanase (EG), exoglicanase ou celobiohidrolase $(\mathrm{CBH})$ e $\beta$-glicosidase ou celobiase. As endoglicanases são responsáveis pela hidrólise preferencialmente das ligações internas no polímero da celulose, produzindo oligossacarídeos de menor peso molecular, chamados de celodextrinas, além de celobiose. As endoglicanases atacam de forma mais ou menos aleatória as ligações $\beta$-(1-4)glicosídicas em regiões amorfas da celulose ou na superfície das microfibrilas. As exoglicanases ou celobiohidrolases iniciam a hidrólise nas extremidades da cadeia e não produzem uma quantidade significativa de novas cadeias terminais na superfície da celulose. As celobiohidrolases são subdivididas em dois grupos: $\mathrm{CBH}$ I e $\mathrm{CBH}$ II, que quebram as unidades de celobiose das extremidades redutora e não redutora do polímero, respectivamente. Logo, as exoglicanases liberam a celobiose, rompendo as ligações $\beta$-(1$4)$-glicosídicas. As celobiases ou $\beta$-glicosidades completam a hidrólise, catalisando a hidrólise da celobiose a glicose. Portanto, as celobiases hidrolisam a celobiose e as celodextrinas solúveis em água, produzindo glicose. As exo e endoglicanases são inibidas pela celobiose e a ação da $\beta$-glicosidade é frequentemente a etapa limitante na degradação da celulose. Micro-organismos fermentadores de celobiose têm o papel de manter as concentrações de celobiose baixas, evitando a inibição do sistema celulase. Estas fermentações produzem $\mathrm{CO}_{2}, \mathrm{H}_{2}$, ácidos orgânicos (por exemplo, acetato, propionato e butirato) e álcoois. Parte do $\mathrm{H}_{2}$ escapa para atmosfera, o restante é imediatamente consumido pelas metanogênicas ou homoacetogênicas (Rabelo, 2007).

A cadeia de hemicelulose pode sofrer ataques por enzimas hemicelulases ou por ácidos diluídos, em posições intermediárias, nesse caso, são liberados oligômeros (moléculas de açúcares) que podem ser sucessivamente quebrados em oligômeros ainda menores, até que uma molécula de um simples açúcar possa ser formada. A eficiência de recuperação de açúcares pode chegar a 90\% (Lynd et al., 2002).

$\mathrm{Na}$ acidogênese, as bactérias fermentativas promovem a conversão de monômeros orgânicos em hidrogênio, bicarbonato, ácido acético, ácido propiônico, ácido butírico, ácido lático (além de outros ácidos em menores proporções) e etanol. Posteriormente ocorre a acetogênese, em que compostos orgânicos reduzidos (como os ácidos propiônico, butírico e lático) são oxidados, gerando hidrogênio e gás carbônico pelos micro-organismos formadores de hidrogênio e pelos micro-organismos formadores de acetato. $\mathrm{O}$ acetato também pode ser formado pela rota do $\mathrm{H}_{2} / \mathrm{CO}_{2}$ em uma etapa chamada homoacetogênese. Finalmente, os produtos finais $\mathrm{CH}_{4} \mathrm{e} \mathrm{CO}_{2}$ podem ser formados na etapa da metanogênese, em que as archeas metanogênicas são capazes de utilizar substratos como $\mathrm{H}_{2}$ e $\mathrm{CO}_{2}$, acetato, formiato e compostos metilados. De todo metano produzido, $70 \%$ é formado na rota do acetato pelas archeas metanogênicas acetoclásticas e 30\% na rota do $\mathrm{H}_{2} / \mathrm{CO}_{2}$ pelas archeas metanogênicas hidrogenotróficas (Pavlostathis e Giraldo-Gomez, 1991).

Bactérias sintróficas desempenham um papel fundamental na conversão de celulose à $\mathrm{CH}_{4} \mathrm{e}$ $\mathrm{CO}_{2}$. Estes organismos fermentam ácidos graxos, 
como propionato e butirato, ou álcoois, e produzem $\mathrm{CO}_{2}$, acetato e $\mathrm{H}_{2}$ (Miller, 1991).

$\mathrm{Hu}$ e $\mathrm{Yu}$ (2005) estudaram a fermentação anaeróbia de resíduos de milho, usando micro-organismos do rúmen como inóculo em reatores do tipo batelada e semicontínuo. Com este sistema, os autores conseguiram converter entre 65 e 70\% da matéria lignocelulósica em metano. Chanakya et al. (1997) avaliaram o PPM do bagaço de cana-de-açúcar bruto e a eficiência de remoção de sólidos voláteis (SV), verificando que, após 90 dias de fermentação, aproximadamente $43 \%$ dos SVs foram degradados, o que resultou em um PPM de 0,83 $\mathrm{m}^{3} \mathrm{CH}_{4} / \mathrm{kgSV}$. Após 30 dias de fermentação apenas 20\% dos SVs haviam sido degradados.

\section{Fatores que afetam a digestão anaeróbia do material lignocelulósico}

A estrutura do material lignocelulósico é composta por microfibrilas celulósicas, que estão envoltas por uma matriz amorfa de polioses e lignina (Ramos, 2003). Isto impede o acesso das enzimas durante o processo de digestão anaeróbia. Além disto, características intrínsecas da celulose, como cristalinidade e grau de polimerização também podem influenciar a sua disponibilidade para os micro-organismos (Fernandes et al., 2009).

Para Wyman (1996) e Hendriks e Zeeman (2009), a cristalinidade da celulose, sua área de superfície acessível, estrutura da lignina e hemicelulose, grau de polimerização da celulose, encontram-se entre os fatores que mais afetam a biodegradabilidade anaeróbia de material lignocelulósico.

A celulose é um homopolissacarídeo linear formado de unidades de glicose unidas por ligações glicosídicas do tipo $\beta$ (1-4). As cadeias de celulose agregam-se, formando fibrilas através de pontes de hidrogênio intra e intercadeias entre os grupamentos hidroxila, o que resulta na cristalinidade da celulose (Tamanini, 2004). As pontes de hidrogênio, inter e intramoleculares, mantêm as regiões cristalinas e torna a celulose resistente à hidrólise ácida, alcalina ou enzimática (Murphy e Mccarthy, 2005).

Apesar de a celulose possuir ligações glicosídicas nos carbonos 1 e 4, a forma como essas unidades de glicose estão ligadas torna a estrutura da celulose diferente em relação à amilose. Esta diferença na estrutura é significativa porque enquanto muitos micro-organismos e animais possuem enzimas necessárias para quebrar as ligações beta-1,4 encontradas no amido ou no glicogênio, poucos seres vivos podem hidrolisar as ligações glicosídicas $\beta$ (1-4) presentes na celulose. Porém, a resistência da celulose à degradação está mais relacionada com a sua estrutura cristalina e ao seu empacotamento do que às ligações glicosídicas citadas anteriormente (Kiipper, 2009).

A maior parte da estrutura da celulose possui fibrilas altamente ordenadas, constituindo a região cristalina firmemente compactada, na qual moléculas de água não conseguem penetrar, tornando a celulose insolúvel em água, dificultando a biodegradação. As regiões amorfas são porções menos ordenadas que, em geral, compreendem aproximadamente $15 \%$ da estrutura celulósica (Kiipper, 2009).

Outro fator que interfere na digestão anaeróbia é o grau de polimerização (GP) da celulose, o que determina a quantidade das ligações beta-glicosídicas das regiões terminais e interiores, e a concentração de substratos para a ação das enzimas exo e endoglucanases, respectivamente. $\mathrm{O}$ aumento da GP da celulose reduz drasticamente a sua solubilidade devido a ligações de hidrogênio intermoleculares. O que determina uma alteração no GP durante a hidrólise é a relativa proporção das atividades de exo e endoglucanases e das propriedades da celulose, pois as exoglucanases causam um aumento no GP ao agir nas extremidades da cadeia, enquanto as endoglucanases causam uma redução no GP, pois hidrolisam preferencialmente as ligações internas do polímero (Zhang e Lynd, 2004).

A superfície dos materiais lignocelulósicos também afeta a hidrólise enzimática porque a estrutura da celulose é incrustada por lignina, o que impede o acesso de celulases a celulose e está envolta pela hemicelulose. Portanto, a hidrólise enzimática de hemicelulose é essencial para os rendimentos mais elevados de hidrólise da celulose (Chandra et al., 2007). Porém, o fator limitante da hidrólise da celulose pura não é a superfície da celulose, mas sim a dificuldade de hidrólise da sua parte cristalina. Portanto, pode-se esperar uma menor taxa de hidrólise após a hidrólise da celulose amorfa. A taxa de hidrólise é normalmente muito alta no início e diminui nas fases posteriores. A superfície específica, ou área da superfície acessível por grama de substrato, 
aumenta acentuadamente durante a fase inicial da hidrólise (Fan et al., 1980). No entanto, este fator não deve ser analisado isoladamente, pois conforme mencionado anteriormente, a taxa de hidrólise diminui à medida que a celulose amorfa é hidrolisada, enquanto a superfície específica aumenta.

Segundo Taherzadeh e Karimi (2008), materiais lignocelulósicos têm dois diferentes tipos de superfície: externo e interno. A superfície externa está relacionada ao tamanho e forma das partículas, enquanto a superfície interna depende da estrutura capilar das fibras celulósicas. Quando a biomassa lignocelulósica passa pelo pré-tratamento físico de secagem, há uma redução no tamanho das fibras, resultando em um colapso irreversível, encolhimento capilar e consequente redução da área de superfície acessível. Para reduzir esse efeito negativo para a digestão anaeróbia, pode-se provocar um inchaço do material lignocelulósico com água e solventes polares, o que aumenta a área de superfície interna (Fan, et al., 1980).

A lignina atua como uma barreira mecânica e é responsável pela integridade, rigidez estrutural, impermeabilidade e resistência ao ataque enzimático. Logo, a concentração e a estrutura da lignina na matriz celulósica também afetam a biodegradabilidade, já que esta ocorre via exoenzimas (Gallert e Winter, 2005). Portanto, o processo de deslignificação pode melhorar a taxa e extensão da hidrólise enzimática e, por consequência, a digestão anaeróbia (Wyman, 1996). A Tabela 1 apresenta o percentual de celulose, hemicelulose e lignina presentes em diferentes resíduos lignocelulósicos.

Para aumentar a biodegradabilidade da celulose, a lignina não precisa ser removida completamente, apenas aquela que está envolvendo as microfibrilas de celulose. Por outro lado, a lignina dissolvida após o pré-tratamento do material lignocelulósico também é um inibidor de celulase, oxilanase e glucosidase (Berlin et al, 2006). Esta inibição ocorre porque a lignina é um heteropolímero formado por unidades fenil-propano que, ao ser hidrolisado, formam compostos tóxicos como compostos aromáticos, fenólicos e aldeídicos (Tamanini, 2004).

\section{Pré-tratamento do material lignoceluló- sico}

O pré-tratamento do material lignocelulósico tem como objetivo melhorar a hidrólise por meio da alteração ou remoção de obstáculos estruturais, facilitando a sua conversão em açúcares fermentescíveis a partir da celulose (glucose) ou hemicelulose (xilose, arabinose, glucose, manose e galactose) (Fernandes et al., 2009). Cada pré-tratamento tem seu próprio efeito sobre a celulose, hemicelulose e lignina. O pré-tratamento mais adequado a ser dado a um determinado resíduo é aquele que promove uma maior conversão de celulose e hemicelulose em açúcares fermentescíveis ou que proporciona melhor acessibilidade da celulose por enzimas hidrolíticas (Taherzadeh e Karimi, 2008). No entanto, se o objetivo é a conversão do material hidrolisado em metano, a formação de compostos tóxicos, como furfural e 5-hidroximetilfurfural (HMF) ou mesmo a solubilização da lignina devem ser considerados como fatores limitantes dos processos biológicos. Além disto, um rigoroso estudo deve ser feito para determinar as melhores opções de tratamento que sejam viáveis, técnica e economicamente.

Desta forma, o processo de pré-tratamento deverá atender aos seguintes requisitos: (a) aumentar a produção de reativos que favoreçam o ataque enzimático das fibras celulósicas, (b) evi-

\begin{tabular}{l|c|c|c|c}
\multicolumn{1}{c|}{ Resíduos Lignocelulósicos } & Celulose (\%) & Hemicelulose (\%) & Lignina(\%) & Referências Bibliográficas \\
\hline Bagaço de cana & 38,9 & 26 & 23,9 & Bustos et al., 2003 \\
\hline Palha de colza & 36,6 & 25 & 17 & Díaz et al., 2010 \\
\hline Palha de trigo & 35 & 22,3 & 15,6 & Petersen et al., 2009 \\
\hline Hastes de algodão & 31,1 & 10,7 & 30,1 & Silverstein et al., 2007 \\
\hline Torta de dendê & 30,4 & 8,07 & 16,65 & Bringel et al., 2011 \\
\hline Palha de sorgo & 34 & 24 & 20 & Herrera et al., 2004 \\
\hline Línter de algodão & \multicolumn{2}{|c|}{$87,43^{*}$} & 3,65 & Silva e Silva Jr., 2006
\end{tabular}

*Fração holocelulósica

Tabela 1: Percentual de lignina em diferentes resíduos lignocelulósicos 
tar a destruição de hemicelulose e celulose, (c) evitar a formação de possíveis inibidores de enzimas hidrolíticas e micro-organismos da fermentação, (d) minimizar a demanda de energia, (e) reduzir o custo relacionado com pré-tratamento físico das matérias-primas, (f) reduzir custo de investimento relacionado com os reatores químicos, (g), produzir menos resíduos e (h) reduzir o consumo de produtos químicos e uso de produtos químicos mais baratos (Taherzadeh e Karimi, 2008).

Vários métodos são utilizados para pré-tratamento de materiais lignocelulósicos antes da hidrólise enzimática, fermentação alcoólica ou da digestão anaeróbia. Esses métodos são classificados em: pré-tratamento físico, pré-tratamento físico-químico, pré-tratamento químico e pré-tratamento enzimático. A seguir será feita uma abordagem geral sobre os pré-tratamentos mais utilizados.

\section{Pré-tratamento físico}

Os principais pré-tratamentos físicos empregados em materiais lignocelulósicos destinados à produção de biocombustíveis são: moagem, irradiação, cisalhamento, esmagamento e pirólise. No entanto, o custo e a finalidade a que se destinará o material lignocelulósico são relevantes na escolha do método, no caso de produção de biogás a moagem é a mais utilizada por diversos pesquisadores (Mshandete, et al., 2006). Dentre esses se pode destacar a moagem, cujo objetivo é diminuir o tamanho e a cristalinidade da partícula; reduzir o grau de polimerização (GP) e aumentar a superfície específica disponível ou superfície acessível; aumentar a capacidade de adsorção, acelerando o processo de hidrólise. Com a moagem, o material lignocelulósico pode ser reduzido a dimensões entre 0,2 e $2 \mathrm{~mm}$ (Sun e Cheng, 2002).

O aumento da superfície específica, a redução do GP e o cisalhamento são fatores que aumentam o rendimento de hidrólise total do material lignocelulósico, na maioria dos casos, em 5 a 25\% (dependendo do tipo de biomassa, tipo de moagem e da duração da moagem), reduzindo o tempo de digestão entre 23 e 59\% (Hendriks e Zeeman, 2009). Chang et al. (1998) observaram a capacidade de hidrólise do bagaço e palha de trigo moído tratado com hidróxido de cálcio $(0,1$ a $0,15 \mathrm{gCa}(\mathrm{OH})_{2} /$ gbiomassa) e constataram que a redução de tamanho da partícula para dimen- sões inferiores a 40 mesh $(0,42 \mathrm{~mm})$ tem pouco efeito sobre a hidrólise. Provavelmente, a superfície específica não aumentou nessas condições. Sharma et al. (1988) encontraram um aumento de $56 \%$ na produtividade máxima de metano de amostras de grama quando o tamanho das partículas foi diminuído de $30 \mathrm{~mm}$ para $1 \mathrm{~mm}$. Fan et al. (1980) mostraram que o índice de cristalinidade da celulose microcristalina diminuiu de $74,2 \%$ para $4,9 \%$, usando um moinho de bolas. Estes resultados estão de acordo com Pabón-Pereira (2009), que concluiu que o aumento da superfície acessível de materiais lignocelulósicos induz ao aumento da biodegradabilidade. No entanto, deve-se considerar o teor de celulose em relação à lignina, isso porque se espera que haja uma maior influência da moagem em amostras contendo partículas de material mais biodegradável do que naqueles com maiores quantidades de material não biodegradável.

Apesar das vantagens da moagem do material lignocelulósico antes da digestão anaeróbia, é importante considerar a exigência de energia mecânica para a redução do tamanho dos mesmos, a qual depende das características deste material e do tamanho final da partícula (Cadoche e López, 1989). Em geral, recomenda-se a diminuição do tamanho das partículas antes da digestão anaeróbia (Deublein e Steinhauser, 2008).

Segundo Zhang e Lynd (2004), a superfície externa está intimamente ligada à forma e ao tamanho das partículas, sendo apenas uma pequena fração da área total. Portanto, o aumento da hidrólise da celulose com a diminuição de tamanho e alteração na forma das partículas poderia não só ser devido ao aumento da área externa, mas também devido a uma diminuição da resistência de transferência de massa.

\section{Pré-tratamento físico-químico}

Os principais pré-tratamentos físico-químicos empregados em materiais lignocelulósicos destinados à produção de biocombustíveis são: hidrólise hidrotérmica, hidrólise com ácido diluído ou concentrado, hidrólise alcalina, explosão a vapor e hidrólise enzimática (Taherzadeh e Karimi, 2008; Hendriks e Zeeman, 2009).

\section{Hidrólise hidrotérmica}

No pré-tratamento hidrotérmico, a hemicelulose é solubilizada em água, utilizando temperaturas elevadas para promover a liberação de ácido acé- 
tico proveniente da hidrólise dos radicais acetila da hemicelulose, que funciona como catalisador da hidrólise, aumentando a acessibilidade da celulose. No entanto, dependendo da severidade do pré-tratamento, a degradação catalítica de açúcares pode ocorrer, formando furfural e hidroximetilfurfural (HMF). Para evitar isto, deve-se manter o pH entre 4 e 7 para minimizar a formação de monossacarídeos e reduzir a formação dos subprodutos da degradação dos açúcares (Mosier et al., 2005). Além disto, quanto maior a quantidade de água, menor será a concentração de lignina solúvel (devido à diluição) e, consequentemente, o risco de condensação e precipitação da lignina e hemicelulose sobre a superfície celulósica é reduzido (Nizami et al., 2009).

Laser et al. (2002) compararam o desempenho do pré-tratamento hidrotérmico com o pré-tratamento com explosão a vapor, utilizando bagaço de cana como substrato, o qual foi posteriormente utilizado na produção de etanol. As seguintes condições foram analisadas: temperatura entre 170 e $230{ }^{\circ} \mathrm{C}$, tempo de reação entre $1 \mathrm{e}$ 46 min., concentração de sólidos entre 1\% e 8\%. Os resultados mostraram que o pré-tratamento hidrotérmico resultou em uma melhor recuperação da xilana em relação ao pré-tratamento com explosão a vapor. Sob condições ótimas $\left(200{ }^{\circ} \mathrm{C}\right.$, 2 min., 5\% de sólidos), os resultados do pré-tratamento hidrotérmico foram comparáveis com processos de pré-tratamento com ácido diluído, no entanto, apresenta a vantagem de não utilizar ácido e ainda, de não haver a produção de resíduos de neutralização.

Petersen et al. (2009), em seus estudos com palha de trigo, buscaram maximizar a recuperação de açúcares (pentoses e hexoses) e conversibilidade de parte das fibras de celulose em etanol por meio do pré-tratamento hidrotérmico, que que seis condições de pré-tratamentos diferentes foram investigadas. Os experimentos mostram que as condições ideais foram $195{ }^{\circ} \mathrm{C}$ por 6 a 12 min. Nessas condições, aproximadamente $70 \%$ da hemicelulose e $94 \%$ da celulose foram recuperadas das fibras. Além disto, aproximadamente $89 \%$ da celulose recuperada pôde ser convertida em etanol, usando complexos enzimáticos comerciais de celulase, com um aumento para $92 \%$ ao adicionar xilanase comercial.

\section{Hidrólise Ácida}

O processo de hidrólise ácida consiste no aque- cimento da biomassa imersa em uma solução ácida (Bevilaqua, 2010), sendo realizado tanto com tempo de reação curto (por exemplo, 5 min.) em alta temperatura (por exemplo, $180{ }^{\circ} \mathrm{C}$ ) ou com tempo de retenção relativamente longo (por exemplo, $90 \mathrm{~min}$.) em temperaturas mais baixas (por exemplo, $120{ }^{\circ} \mathrm{C}$ ). A solução de ácido pode ser concentrada $(>10 \%)$ ou diluída $(0,1$ a $10 \%)$, sendo usualmente empregados como catalisadores o ácido sulfúrico, ácido clorídrico, ácido nítrico ou ácido fosfórico. A hidrólise ácida é um processo rápido, tem baixo consumo de energia e um alto rendimento em termos açúcares redutores (Taherzadeh e Karimi, 2008).

Os produtos da hidrólise ácida dos materiais lignocelulósicos são os açúcares fermentescíveis, como a glicose, proveniente da celulose; e xilose, manose, galactose, glicose e arabinose, provenientes da hemicelulose. No entanto, dependendo da severidade do pré-tratamento (Pedersen e Meyer, 2010), os açúcares formados podem ser degradados, formando furfural e HMF, e estes podem ser degradados em ácido fórmico e ácido levulínico (Palmqvist e Hahn-Hägerdal, 2000). As cinéticas de todas estas reações são afetadas pelo tipo e tamanho do material lignocelulósico, bem como pelos parâmetros operacionais dos diversos métodos de pré-tratamento, como: tipo e concentração do ácido, pressão, temperatura e tempo de reação.

A hidrólise com ácido concentrado, usando $\mathrm{H}_{2} \mathrm{SO}_{4}$ com concentração entre 30 e $70 \%$, e temperatura na ordem de $40{ }^{\circ} \mathrm{C}$, tem sido utilizada para tratar de diversos tipos de materiais lignocelulósicos (Sarrouh et al., 2005). Apesar de esses catalisadores serem eficazes para a hidrólise de celulose, os ácidos concentrados podem ser tóxicos, corrosivos e perigosos, e requerem reatores que sejam resistentes a estas condições extremas de corrosão. É importante considerar ainda que, após a hidrólise, o ácido concentrado deve ser recuperado de maneira a viabilizar economicamente o processo (Sivers e Zacchi, 1995).

Para a hidrólise com ácido diluído, normalmente se utiliza uma solução com concentração na faixa de 0,1 a $10 \%$ e temperatura entre 100 e $160{ }^{\circ} \mathrm{C}$, empregando ácido sulfúrico $\left(\mathrm{H}_{2} \mathrm{SO}_{4}\right)$, ácido clorídrico $(\mathrm{HCl})$, ácido fosfórico $\left(\mathrm{H}_{3} \mathrm{PO}_{4}\right) \mathrm{e}$ ácido nítrico $\left(\mathrm{HNO}_{3}\right)$ (Lavarack et al., 2002; Aguilar et al., 2002; Bevilaqua, 2010), sob essas condições é possível alcançar um rendimento razoável em termos de solubilização da hemicelulose (Car- 
valheiro et al., 2008). Durante este processo, os grupos acetil ligados à hemicelulose são clivados e também passam a atuar como catalisadores da hidrólise. Como consequência destas reações, a estrutura da parede vegetal passa por alterações extremas, como hidrólise da hemicelulose e/ou solubilização da lignina, favorecendo a acessibilidade da celulose pelas exoenzimas. No entanto, grande parte da hemicelulose é degradada e a lignina permanece praticamente inalterada. Apesar de haver despolimerização da lignina durante o pré-tratamento com ácido diluído, também há repolimerização e redistribuição superficial, o que implica uma possível diminuição da biodegradabilidade (Canilha et al., 2010).

$\mathrm{Na}$ hidrólise com ácido diluído, a hemicelulose é despolimerizada em temperatura mais baixa do que a celulose, da mesma forma que ocorre quando se utiliza ácido concentrado. No entanto, este último processo propicia a formação de inibidores devido à degradação da hemicelulose em furfural. Além disto, se uma maior temperatura ou maior tempo de retenção são aplicados, os monossacarídeos formados serão posteriormente hidrolisados, acelerando a formação de furfural e HMF. Portanto, deve-se evitar a degradação dos monossacarídeos de modo a melhorar o rendimento da hidrólise. Alguns autores recomendam que o processo de hidrólise seja realizado em pelo menos dois estágios, a primeira fase em condições relativamente suaves, durante a qual a fração de hemicelulose é hidrolisada, e uma segunda fase pode ser realizada por hidrólise enzimática ou hidrólise com ácido diluído a temperaturas mais altas, durante a qual a celulose é hidrolisada (Sánchez et al., 2004).

Sarrouh et al. (2005), em seus estudos com bagaço de cana-de-açúcar, conseguiram uma taxa máxima de conversão de açúcares fermentescíveis de $97,5 \%$, utilizando concentração de $\mathrm{H}_{2} \mathrm{SO}_{4}$ de $30 \%, 2 \%$ de sólidos e uma temperatura de $50{ }^{\circ} \mathrm{C}$ por $1 \mathrm{~h}$. Aguilar et al. (2002) realizaram estudos para produzir xilose a partir da hidrólise do bagaço de cana-de-açúcar com $\mathrm{H}_{2} \mathrm{SO}_{4}$ a temperaturas entre 100 e $128^{\circ} \mathrm{C}$ e concentrações entre 2 e $6 \%$. A condição ótima encontrada foi a concentração de $\mathrm{H}_{2} \mathrm{SO}_{4}$ de $2 \%$ com temperatura de $122{ }^{\circ} \mathrm{C}$ durante 24 min. Com estes parâmetros, o hidrolisado formado continha 21,6 g/L de xilose, 3,0 g/L de glicose, 0,5 g/L de furfural e 3,65 g/L de ácido acético. Nestas condições, 90\% da hemicelulose foi hidrolisada. Bustos et al. (2003) também realizaram experimentos com bagaço de cana-de-açúcar, usando $\mathrm{HCl}$ entre 2 e $6 \%$, tempos de reação entre 0 e 300 min. e temperaturas entre 100 e $128{ }^{\circ} \mathrm{C}$. A condição ótima encontrada foi: temperatura de $128{ }^{\circ} \mathrm{C}$, concentração de $2 \%$ de $\mathrm{HCl}$ e tempo de reação de 51,1 min. O hidrolisado continha 22,6 g/L de xilose, 3,31 g/L de arabinose, 3,59 g/L de ácido acético e 1,54 g/L de furfural.

Gámez et al. (2006) realizaram hidrólise com bagaço de cana-de-açúcar, utilizando ácido fosfórico com concentração entre 2 e $6 \%$, tempos de reação entre 0 e 300 min. e temperatura de $122{ }^{\circ} \mathrm{C}$ para usar o hidrolisado como substrato para fermentação. A condição ótima encontrada foi $4 \%$ de $\mathrm{H}_{3} \mathrm{PO}_{4}$ e temperatura de $122{ }^{\circ} \mathrm{C}$ durante 300 min. Dentro dessas condições o hidrolisado obtido foi analisado e obteve-se 17,6 g/L de xilose; 2,6 g/L de arabinose; 3,0 g/L de glicose; e $1,2 \mathrm{~g} / \mathrm{L}$ de furfural e $4 \mathrm{~g} / \mathrm{L}$ de ácido acético.

Rodríguez-Chong et al. (2004) realizaram experimentos com bagaço de cana-de-açúcar, utilizando $\mathrm{HNO}_{3}$ (concentração entre 2 e 6\%), tempos de reação entre 0 e 300 min. e temperatura entre 100 e $128{ }^{\circ} \mathrm{C}$. A condição ótima encontrada foi temperatura de $122{ }^{\circ} \mathrm{C}$, concentração de $6 \%$ de ácido nítrico durante 9,3 min. O hidrolisado obtido na condição ótima consistia de 18,6 g/L de xilose; 2,04 g/L de arabinose; 2,87 g/L de glicose; $0.9 \mathrm{~g} / \mathrm{L}$ de ácido acético e 1,32 g/L de furfural.

Ao se analisar os resultados obtidos nos experimento com diferentes ácidos $\left(\mathrm{H}_{2} \mathrm{SO}_{4}, \mathrm{HCl}, \mathrm{H}_{3} \mathrm{PO}_{4}\right.$ e $\mathrm{HNO}_{3}$ ), conforme apresentado nos parágrafos anteriores, é possível observar que a maior eficiência de conversão dos materiais lignocelulósicos em açúcares foi alcançada quando $\mathrm{HCl}$ foi utilizado, no entanto, houve um aumento da concentração de furfural, que é inibidor microbiano. Porém, as concentrações encontradas não representam riscos de inibição para o consórcio anaeróbio.

$\mathrm{O}$ pré-tratamento com $\mathrm{H}_{3} \mathrm{PO}_{4}$ alcançou uma boa conversão em açúcares quando comparada aos outros experimentos, no entanto, a concentração de ácido exigida para a hidrólise foi duas vezes maior que a concentração adotada para $\mathrm{H}_{2} \mathrm{SO}_{4}$ e $\mathrm{HCl}$, e o tempo de reação foi muito superior, o que pode implicar um custo elevado de operação. $\mathrm{O} \mathrm{H}_{2} \mathrm{SO}_{4}$ apresentou uma taxa elevada de hidrólise $(90 \%)$, no entanto, em se tratando de digestão anaeróbia essa opção deve ser descartada, pois a produção de metano pode ser 
reduzida em virtude da competição das archaeas metanogênicas com as bactérias redutoras de sulfato (BRS), em virtude do $\mathrm{SO}_{4}^{-2}$ oriundo da reação (Chernicharo, 2007). Segundo Hendriks e Zeeman (2009), o pré-tratamento com ácido sulfúrico pode limitar a produção do metano em detrimento da produção de $\mathrm{H}_{2} \mathrm{~S}$. Na presença de sulfato, muitos dos compostos intermediários da digestão anaeróbia passam a ser utilizados pelas BRS. Nessas condições, estas bactérias passam a competir com as bactérias fermentativas, acetogênicas e archeas metanogênicas, pelos substratos disponíveis. Essa competição torna-se mais significativa quanto menor a relação $\mathrm{DQO} / \mathrm{SO}_{4}^{-2}$ (Chernicharo, 2007). Segundo este último autor, uma competição mais significativa só ocorre quando a relação $\mathrm{DQO} / \mathrm{SO}_{4}^{-2}$ é inferior a 7 , mas com forte dependência do $\mathrm{pH}$.

$\mathrm{O}$ pré-tratamento com $\mathrm{HNO}_{3}$ mostrou-se bastante interessante, pois o tempo de reação foi bem inferior aos demais, apesar da maior concentração de ácido exigida, pois este ácido é mais fraco. $\mathrm{O}$ uso de $\mathrm{HNO}_{3}$ também pode resultar em menor produção de metano, pois há competição das archaeas metanogênicas com as bactérias redutoras de nitrato (BRN), formando $\mathrm{N}_{2}$ (Hendriks e Zeeman, 2009). Pode-se então considerar, dentre os trabalhos analisados, que o $\mathrm{HCl}$ mostrou ser o catalizador que melhor se aplica ao pré-tratamento de materiais lignocelulósicos destinados à digestão anaeróbia.

\section{Hidrólise alcalina}

O pré-tratamento alcalino é normalmente empregado em materiais lignocelulósicos in natura com estrutura morfológica rígida, com alto teor de lignina, em que são necessárias condições de reação mais severas, como por exemplo, concentração de álcali maior que $10 \%$ e temperatura acima de $150{ }^{\circ} \mathrm{C}$ (Oliveira, 2010). De acordo com Carvalheiro et al. (2008), a temperatura utilizada deve estar na faixa de 30 e $130{ }^{\circ} \mathrm{C}$ e o tempo de reação entre $10 \mathrm{~min}$. e $18 \mathrm{~h}$, sendo que quanto maior a temperatura menor será o tempo de reação e vice-versa.

A hidrólise alcalina se dá pelo uso de um catalisador alcalino que provoca rompimento nas ligações éster entre hemicelulose e lignina. Com o rompimento destas ligações, há um inchaço no material, aumento na porosidade do material e consequente aumento da superfície acessível pelas exoenzimas. Segundo Sun e Cheng (2002), o catalisador alcalino, como o $\mathrm{NaOH}$, diminui o grau de polimerização e a cristalinidade, levando à ruptura da estrutura da lignina. Dessa forma, o pré-tratamento alcalino aumenta a biodegradabilidade da celulose.

Dependendo do catalisador utilizado, os pré-tratamentos alcalinos podem ser divididos em dois principais grupos: os que utilizam soluções de bases como catalisador, como hidróxido de sódio, hidróxido de potássio ou hidróxido de cálcio, e pré-tratamentos que utilizam amônia. Ao contrário dos processos que utilizam ácidos, o da hidrólise alcalina é mais eficaz para a solubilização de lignina, havendo pequena solubilização da celulose e hemicelulose, com exceção do tratamento com percolação de amônia, que remove a lignina e degrada a hemicelulose, gerando um hidrolisado contendo principalmente celulose (Carvalheiro et al., 2008).

O hidróxido de cálcio (cal hidratada) e hidróxido de sódio são os catalisadores mais comuns utilizados no pré-tratamento alcalino. Em geral, utilizam-se concentrações entre 0,05 e 0,15 gramas de alcaloide por grama de biomassa, aplicadas diretamente a uma batelada de biomassa ou como um posterior tratamento da biomassa hidrolisada com um ácido (Vázquez, 1992; Moldes et al., 2002).

Fernandes et al. (2009) estudaram os efeitos de pré-tratamentos termo-químicos (hidróxido de cálcio, carbonato de amônio e ácido maléico) sob a biodegradabilidade anaeróbia e hidrólise de biomassa lignocelulósica (feno, palha e sabambaia) e chegaram à conclusão de que quando o teor de lignina do material vegetal é alto, pré-tratamentos termo-químicos têm um efeito positivo sobre a biodegradabilidade do substrato. Pré-tratamento com hidróxido de cálcio melhora a biodegradabilidade de biomassa lignocelulósica, especialmente para substratos com alto teor de lignina, como a samambaia. Como dito anteriormente, a lignina funciona como uma barreira física ao ataque biológico e sua remoção implica melhora da biodegradabilidade, pois o acesso enzimático a fração holocelulósica (celulose e hemicelulose) é favorecido.

Chang et al. (1998) avaliaram a hidrólise do bagaço e palha de trigo com cal e concluíram que, para tempos de reação curtos (entre 1 e 3 h), são necessárias temperaturas elevadas (entre 85 e $135^{\circ} \mathrm{C}$ ) para garantir um pré-tratamento eficaz. Por outro lado, para tempos longos de pré-trata- 
mento (por exemplo, $24 \mathrm{~h}$ ), temperaturas entre 50 e $65^{\circ} \mathrm{C}$ são suficientes para atingir rendimentos elevados de conversão de celulose e hemicelulose em açúcares. Os autores concluíram ainda que $85 \%$ dos açúcares podem ser liberados em 24 h de hidrólise.

A Cal, em comparação com $\mathrm{NaOH}$ e $\mathrm{KOH}$, tem menor custo e requer menos requisitos de segurança. Ela pode ser recuperada a partir do hidrolisado por reação com o $\mathrm{CO}_{2}$, de modo que o carbonato formado pode ser reconvertido para cal. Ao contrário do pré-tratamento com catalisador ácido, a limitação ocorre porque alguns álcalis são convertidos em sais inconversíveis ou incorporados na biomassa (Mosier et al., 2005).

\section{Explosão a vapor}

Esse método consiste em submeter a biomassa à alta pressão de vapor saturado e, em seguida, liberação súbita da pressão. Com isto, o material lignocelulósico sofre uma descompressão explosiva (Sun e Cheng, 2002). O processo provoca a degradação da hemicelulose e da lignina devido à alta temperatura, além de causar exposição das fibras, aumentando o potencial de hidrólise da celulose. $\mathrm{O}$ pré-tratamento usando explosão a vapor é normalmente empregado a temperaturas entre 160 e $260{ }^{\circ} \mathrm{C}$ (correspondente pressão de 0.69 e 4,83 $\mathrm{MPa}$ ) durante alguns segundos a alguns minutos, antes de o material ser exposto à pressão atmosférica. Os fatores que afetam a eficiência deste pré-tratamento são o tempo de reação, temperatura, tamanho das fibras do material e teor de umidade. A solubilização e hidrólise da hemicelulose podem ser alcançadas tanto em altas temperaturas e curto tempo de residência (por exemplo, $270{ }^{\circ} \mathrm{C}, 1 \mathrm{~min}$.), quanto baixa temperatura e maior tempo de residência (por exemplo, $190{ }^{\circ} \mathrm{C}, 10 \mathrm{~min}$.) (Duff e Murray, 1996).

A Tabela 2 (pag. 46) apresenta o relato de alguns autores que estudaram pré-tratamento físico-químico de materiais lignocelulósicos.

\section{Pré-tratamento Enzimático}

A hidrólise da celulose em glicose catalisada pelas enzimas celulase possui uma taxa de rendimento muito baixa (menor que 20\%), isso se deve principalmente à estrutura altamente cristalina da celulose. A dificuldade aumenta também porque a celulose é adsorvida fisicamente pela lignina, que funciona como uma barreira, protegendo a superfície celulósica e impedindo o intumescimento das fibras. Uma etapa de pré-tratamento anterior ao pré-tratamento enzimático é então necessária, de maneira a remover a lignina e diminuir a cristalinidade do material lignocelulósico, expondo as moléculas de celulose e hemicelulose à ação enzimática e aumentando a taxa de hidrólise da celulose a valores superiores a 90\% (Ogeda e Petri, 2010).

A cadeia de hemicelulose pode sofrer ataques por enzimas hemicelulases ou por ácidos diluídos, em posições intermediárias, nesse caso, são liberados oligômeros (moléculas de açúcares) que podem ser sucessivamente quebrados em oligômeros ainda menores, até que uma molécula de um simples açúcar possa ser formada. A eficiência de recuperação de açúcares máxima pode chegar a $90 \%$ (Lynd et al., 2002).

Saha e Cotta (2006), em seu estudo com palha de trigo e casca de arroz, obtiveram 97 e 96\% de conversão a açúcares fermentescíveis após hidrólise enzimática do hidrolisado com peróxido.

\section{Toxicidade anaeróbia}

A produção de metano a partir de material lignocelulósico é composta por três fases: pré-tratamento do material, digestão anaeróbia do hidrolisado e pós-tratamento da fração líquida. Alternativamente, as frações sólida e líquida são mantidas juntas e utilizadas como substrato para produção de metano.

Como mostrado anteriormente, a hemicelulose e lignina dificultam o acesso da celulase à celulose, diminuindo a eficiência da hidrólise, este efeito pode ser minimizado por meio de um pré-tratamento de maneira a melhorar o rendimento da hidrólise e produção de metano. No entanto, durante o processo de pré-tratamento, pode haver a formação de subprodutos tóxicos ou inibidores da etapa metanogênica. Estes compostos podem ser originados em virtude das altas temperaturas ou condições ácidas nas quais se desenvolvem os pré-tratamentos. Segundo Rossell (2006), a natureza e concentração destes compostos dependem: (i) do tipo de matéria-prima (conteúdo percentual de celulose, hemicelulose e lignina); (ii) do pré-tratamento utilizado; (iii) das condições do processo (temperatura e tempo de reação); e (iv) do emprego ou não de catalisadores ácidos. De acordo com Domínguez (2003), os inibidores da fermentação oriundos da degradação de material lignocelulósico são agrupados em três categorias: (i) derivados do furano; (ii) 


\begin{tabular}{|c|c|c|c|c|c|c|c|}
\hline Resíduo & $\begin{array}{l}\text { Pré-trata- } \\
\text { mento }\end{array}$ & Catalisador & $\begin{array}{l}\text { Concentração } \\
\text { (M) }\end{array}$ & $\begin{array}{l}\text { Tempo } \\
\text { (min.) }\end{array}$ & $\begin{array}{c}\text { Temperatura } \\
\left({ }^{\circ} \mathrm{C}\right)\end{array}$ & $\begin{array}{l}\text { Condições } \\
\text { ótimas }\end{array}$ & Referência \\
\hline $\begin{array}{l}\text { Bagaço de cana- } \\
\text {-de-açúcar }\end{array}$ & Ácido & $\mathrm{H}_{2} \mathrm{SO}_{4}$ & $0,2,0,4$ e 0,6 & $0-300$ & 100,122128 & $\begin{array}{c}0,2,122^{\circ} \mathrm{Ce} \\
24 \mathrm{~min}\end{array}$ & $\begin{array}{l}\text { Aguilar et al. } \\
\text { (2002) }\end{array}$ \\
\hline $\begin{array}{l}\text { Bagaço de cana- } \\
\text {-de- açúcar }\end{array}$ & Ácido & $\mathrm{H}_{3} \mathrm{PO}_{4}$ & $0,35-1,03$ & $0-300$ & 122 & $\begin{array}{l}0,68 \mathrm{M}, 300 \\
\min \text { e } 122^{\circ} \mathrm{C}\end{array}$ & $\begin{array}{l}\text { Gámez et al. } \\
\text { (2005) }\end{array}$ \\
\hline Palha de sorgo & Ácido & $\mathrm{H}_{3} \mathrm{PO}_{4}$ & $0.34-1.03$ & $0-300$ & 134 & $\begin{array}{l}1,03 \mathrm{M}, 300 \\
\min \text { e } 134^{\circ} \mathrm{C}\end{array}$ & $\begin{array}{l}\text { Vázquez et al. } \\
\text { (2007) }\end{array}$ \\
\hline Palha de sorgo & Ácido & $\mathrm{HCl}$ & $0.65-1.95$ & $20-300$ & 100 & $\begin{array}{c}1,7 \mathrm{M}, 83 \mathrm{~min} \\
\text { e } 122^{\circ} \mathrm{C}\end{array}$ & $\begin{array}{l}\text { Herrera et al. } \\
\quad(2003)\end{array}$ \\
\hline Palha de sorgo & Ácido & $\mathrm{HCl}$ & $0.65-1.95$ & $0-300$ & 100 & $\begin{array}{c}1,95 \mathrm{M}, 83 \\
\min \text { e } 100^{\circ} \mathrm{C}\end{array}$ & $\begin{array}{l}\text { Herrera } \\
\text { et al.(2004) }\end{array}$ \\
\hline $\begin{array}{l}\text { Bagaço de cana- } \\
\text {-de-açúcar }\end{array}$ & Ácido & $\mathrm{HCl}$ & $0.65-1.95$ & $0-300$ & 100,122 e 128 & $\begin{array}{c}0,9 \mathrm{M}, 51.1 \\
\min \text { e } 128^{\circ} \mathrm{C}\end{array}$ & $\begin{array}{l}\text { Bustos et al. } \\
\text { (2003) }\end{array}$ \\
\hline $\begin{array}{l}\text { Bagaço de cana- } \\
\text {-de-açúcar }\end{array}$ & Ácido & $\mathrm{HNO}_{3}$ & $0.5-1.44$ & $0-300$ & 122 & $\begin{array}{l}1,44 \mathrm{M}, 9,3 \\
\min \text { e } 122^{\circ} \mathrm{C}\end{array}$ & $\begin{array}{l}\text { Rodríguez- } \\
\text {-Chong, (2004) }\end{array}$ \\
\hline Palha de trigo & Hidrotérmico & $\mathrm{H}_{2} \mathrm{O}$ & - & $6-12$ & 185,195 e 205 & $\begin{array}{l}6-12 \min e \\
195^{\circ} \mathrm{C}\end{array}$ & $\begin{array}{l}\text { Petersen et al. } \\
\text { (2009) }\end{array}$ \\
\hline $\begin{array}{l}\text { Bagaço de cana- } \\
\text {-de-açúcar }\end{array}$ & Hidrotérmico & $\mathrm{H}_{2} \mathrm{O}$ & - & até 250 & 150,170 e 190 & $2 \mathrm{~h} \mathrm{e} 150^{\circ} \mathrm{C}$ & $\begin{array}{l}\text { Boussarsar et al. } \\
\text { (2009) }\end{array}$ \\
\hline $\begin{array}{l}\text { Bagaço de cana- } \\
\text {-de-açúcar }\end{array}$ & Hidrotérmico & $\mathrm{H}_{2} \mathrm{O}$ & - & $1-46$ & $170-220$ & $2 \min$ e $220^{\circ} \mathrm{C}$ & $\begin{array}{l}\text { Laser et al. } \\
\quad(2002)\end{array}$ \\
\hline Palha de colza & Hidrotérmico & $\mathrm{H}_{2} \mathrm{O}$ & - & $\begin{array}{l}10,30 \\
\text { e } 50\end{array}$ & 170,190 e 210 & $\begin{array}{l}27 \text { min e } \\
193^{\circ} \mathrm{C}\end{array}$ & $\begin{array}{l}\text { Díaz et al. } \\
\text { (2010) }\end{array}$ \\
\hline $\begin{array}{l}\text { Palha/Feno/ } \\
\text { Samambaia }\end{array}$ & Alcalino & $\mathrm{CaOH}_{2}$ & 0,13 & 960 & 85 & $16 \mathrm{~h}$ e $85^{\circ} \mathrm{C}$ & $\begin{array}{l}\text { Fernandes } \\
\text { et al.(2009) }\end{array}$ \\
\hline Casca de cevada & Alcalino & $\mathrm{NaOH}$ & $0,75-2,5$ & $10-60$ & $50-130$ & $\begin{array}{l}2,5 \mathrm{M}, 35 \\
\min , 130^{\circ} \mathrm{C}\end{array}$ & $\begin{array}{l}\text { Moldes et al. } \\
\quad(2002)\end{array}$ \\
\hline $\begin{array}{l}\text { Haste do algo- } \\
\text { dão }\end{array}$ & Alcalino & $\mathrm{NaOH}$ & $0,08 / 0,53 / 1,07$ & $30 / 60 / 90$ & 121 & $\begin{array}{c}1,06 \mathrm{M}, 90 \\
\min , 121^{\circ} \mathrm{C}\end{array}$ & $\begin{array}{l}\text { Silverstein et al. } \\
\text { (2007) }\end{array}$ \\
\hline Palha de sorgo & $\begin{array}{l}\text { Explosão a } \\
\text { Vapor }\end{array}$ & & & 5 & $190-240$ & $240^{\circ} \mathrm{C}$ & Ruiz et al. (2008) \\
\hline \multirow{2}{*}{ Palha de sorgo } & $\begin{array}{l}\text { Explosão a } \\
\text { vapor }\end{array}$ & $\mathrm{CH}_{3} \mathrm{COOH}$ & & \multirow{2}{*}{$3-60$} & \multirow{2}{*}{$180-225$} & $\begin{array}{l}10 \mathrm{~min}, \\
210^{\circ} \mathrm{C}\end{array}$ & \multirow{2}{*}{ Zabihi (2010) } \\
\hline & $\begin{array}{l}\text { Explosão a } \\
\text { vapor }\end{array}$ & $\mathrm{H}_{2} \mathrm{O} / \mathrm{C}_{2} \mathrm{H}_{6} \mathrm{O}$ & & & & $5 \mathrm{~min}, 220^{\circ} \mathrm{C}$ & \\
\hline
\end{tabular}

Tabela 2: Resultados de pesquisas com pré-tratamento físico-químico de materiais lignocelulósicos.

$<L . Q$ - Abaixo do limite de quantificação / N.D - Não detectado / - limite não estabelecido pela Resolução

* valor referente ao composto na forma dissolvida

ácidos alifáticos de baixa massa molecular; e (iii) derivados fenólicos.

Os compostos derivados do furano são: o furfural, formado a partir da degradação das pentoses (xilose e arabinose) e o HMF, formado como consequência da degradação das hexoses (glicose, manose e galactose). Por sua vez, o furfural pode degradar-se em ácido fórmico e o HMF pode degradar-se em ácido fórmico e levulínico (Canettieri, 2004). Além destes, pode haver formação do ácido acético proveniente da hidrolise dos radicais acetila da hemicelulose.
Dependendo do tipo de pré-tratamento e da severidade do mesmo, a lignina pode degradar-se em uma variedade de compostos fenólicos, como, por exemplo: ácido 4-hidroxibenzóico, originado na ruptura das ligações éster que unem os grupos hidroxilas dos álcoois cinâmicos da lignina; o siringaldeído e o ácido siríngico, procedentes da degradação das unidades siringilpropano da lignina; o 4-hidroxibenzaldeído e os ácidos gentísico, salicílico e protocatéquico (Canettieri, 2004). Este autor mostrou também que, após a degradação da lignina, podem ser gerados: vani- 
lina, ácido vanílico, ácido homovanílico, catecol, guaiacol, eugenol, hidroquinona e aldeído coniferílico.

Além dos compostos já citados, o pré-tratamento de materiais lignocelulósicos propiciam a formação de diferentes tipos de resinas (ácidos graxos, terpenóides, esteróis e ceras) e compostos fenólicos (flavonóides, taninos, etc.) (Domínguez, 2003). Muitas bactérias em condições anaeróbicas transformam ou degradam Furfural. De acordo com Boopathy (2009), as metanogênicas, Methanococcus sp. apresentaram um melhor crescimento em presença de furfural $(5,10$ e $15 \mathrm{mM}$ ) em relação às culturas que não receberam furfural, indicando possível estimulação do crescimento nestas concentrações. De fato, esta bactéria pode reduzir o furfural a álcool furfurílico. Entretanto, as culturas que receberam concentrações entre 25 e $30 \mathrm{mM}$ de furfural foram inibidas. Cao et al. (2010) estudaram o efeito de inibidores derivados de biomassa lignocelulósica sobre o crescimento e produção de hidrogênio por Thermoanaerobacterium thermosaccharolyticum W16 e constataram que concentrações de 0,5 g/L de Furfural e 0,5 g/L de HMF não causaram efeito inibitório sob a produção de hidrogênio.

O álcool furfurílico é um dos intermediários na degradação do furfural por BRS. A única archaea metanogênica que transforma o furfural em álcool furfurílico é a Methanococcus deltae pela redução de 2 elétrons (Belay et al., 1997). Essa transformação do furfural foi observada quando o mesmo não foi utilizado como única fonte de carbono e nem como substrato. Transformações similares a essa também foram observadas em bactérias entéricas (Boopathy et al., 1993). Já as BRS metabolizam furfural e álcool furfurílico produzindo ácido acético, que pode ser eventualmente convertido em metano e $\mathrm{CO}_{2}$ por archaeas metanogênicas acetoclásticas (Belay et al., 1997). A produção de sulfeto pode também provocar efeito inibitório na atividade microbiana. Quando a relação $\mathrm{DQO} / \mathrm{SO}_{4}^{-2}$ for superior a 10 , grande parte do $\mathrm{H}_{2} \mathrm{~S}$ produzido será removida da fase líquida, em virtude da elevada produção de biogás, o qual propicia uma redução do efeito inibidor (Chernicharo, 2007).

Além dos compostos inibitórios já mensionados, a inibição pelo produto (glicose) também deve ser considerada. Isso ocorre quando a concentração de glicose é muito alta, podendo re- primir atividade da celulase, conhecida como inibição “feedback”. Segundo Xiao et al. (2004), $100 \mathrm{~g} / \mathrm{L}$ de glicose causaram 50\% de inibição da hidrólise enzimática da celobiose e, segundo Oh et al. (2000), $5 \mathrm{~g} / \mathrm{L}$ de glicose causaram $80 \%$ de inibição da atividade $\beta$-glucosidase. 0 efeito inibitório foi também observado para outros açúcares, como manose, xilose e galactose, no entanto a glicose foi o único açúcar que inibiu ambas as atividades $\beta$-glucosidae e celulase (Xiao et al., 2004). Por outro lado, concentração baixa de glicose pode estimular a atividade da celulase. Segundo Fernandes (2010), na digestão anaeróbia de resíduos complexos, a glicose geralmente não é detectada porque é imediatamente consumida pelas bactérias.

\section{Discussão final}

Considerando-se que a quantidade de biomassa lignocelulósica despejada diariamente nos pátios das indústrias vem crescendo a cada ano, que, apesar de aproveitada para diversos fins, conforme mencionado neste trabalho, ainda representa impactos ambientais que podem, podem ser minimizados por meio do aproveitamento desses materiais para produção de uma energia limpa, o metano. No entanto, a hidrólise ou a biodegradação de materiais lignocelulósicos apresenta diversas limitações, como: nível de polimerização (DP), teor de umidade, área disponível e teor de lignina. No entanto esses fatores não podem ser analisados separadamente, pois a intervenção sobre um fator pode exercer influência positiva ou não sobre outro e a escolha do pré-tratamento adequado deve levar em conta esses aspectos, não deixando de considerar também as peculiaridades de cada biomassa a ser estudada, como, por exemplo, a concentração de celulose, hemicelulose e lignina.

Cada pré-tratamento apresenta vantagens e limitações, no entanto, sua escolha está relacionada à característica da biomassa e da finalidade do hidrolisado. Se, por exemplo, a biomassa é rica em holocelulose e se pretende maximizar a produção de metano, recomenda-se pré-tratamento com ácido diluído, pois além de solubilizar a hemicelulose apresenta menor geração de inibidores, tornando a celulose mais acessível. No entanto, se a biomassa apresenta elevada fração de lignina, pode-se adotar o pré-tratamento alcalino, pois além de possível aproveitamento da lignina têm-se a fibra rica em celulose e com 
elevada área superficial provocada pelo inchaço da fibra e, consequentemente, maior biodegradabilidade, permitindo maior rendimento em termos de produção de metano.

\section{Referências}

AGUIAR, A. FERRAZ, A. Mecanismos envolvidos na biodegradação de materiais lignocelulósicos e aplicações tecnológicas correlatas. Química Nova, XY, 1-10, 2011.

AGUILAR, R.; RAMÍREZ, J. A.; GARROTE, G.; VÁZQUEZ, M. Kinetic study of the acid hydrolysis of sugar cane bagasse, J. Food Eng., 55, 4, 309-318, 2002.

ANGELIDAKI I.; ALVES, M.; BOLZONELLA, D.; BORZACCONI, L.; CAMPOS J. L.; GUWY, A. J.; KALYUZHNYI, S.; JENICEK, P.; VAN LIER, J. B. Defining the biomethane potential (BMP) of solid organic wastes and energy crops: a proposed protocol for batch assays. Water Sci. Technol., 59, 5, 927-934, 2009.

BELAY, N.; BOOPATHY, R.; VOSKUILEN, G. Anaerobic Transformation of Furfural by Methanococcus deltae $\Delta$ LH. Environ. Microbiol., 63, 5, 2092-2094, 1997.

BERLIN, A.; BALAKSHIN, M.; GILKES, N.; KADLA, J.; MAXIMENKO, V.; KUBO, S.; SADDLER, J. Inhibition of cellulase, xilanase and beta-glucosidase and activities by softwood lignin preparations. J. Biotechnol., 125, 198-209, 2006.

BEVILAQUA, D. B. Produção de ácido levulínico por meio de hidrólise ácida da casca de arroz. Dissertação de Mestrado, Universidade Federal de Santa Maria, Santa Maria - RS, Brasil, 87, 2010.

BOOPATHY, R. Anaerobic biotransformation of furfural to furfuryl alcohol by a methanogenic archaebacterium. In: Int. Biodet. Biodegrad., 63, 1070-1072, 2009.

BOOPATHY, R.; BOKANG, H.; DANIELS, L. Biotransformation of furfural and 5-hydroxymethyl furfural by enteric bacteria. J. Industrial Microbiol., 11, 147-150, 1993

BOUSSARSAR, H.; ROGÉ, B.; MATHLOUTHI, M. Optimization of sugarcane bagasse conversion by hydrothermal treatment for the recovery of xylose. Bioresour. Technol., 100, 6537-6542, 2009.
BRASIL. Ministério de Minas e Energia. Plano Nacional de Energia 2030/MME; colaboração Empresa de Pesquisa Energética. Brasília: MME: EPE, 12, 2007.

BRINGEL, L. M. L.; NEIVA, J. N. M.; ARAÚJO, V. L.; BOMFIM, M. A. D.; RESTLE, J.; CONABCompanhia Nacional de Abastecimento. Acompanhamento de safra brasileira: grãos, quarto levantamento, janeiro/2012. Brasília, 2012.

BUSTOS, G.; RAMÍREZ, J. A.; GARROTE, G.; VÁZQUEZ, M. Modeling of the Hydrolysis of Sugar Cane Bagasse with Hydrochloric Acid. Appl. Biochem. Biotechnol.. 104, 2003.

CADOCHE, L., LOPEZ, G.D. Assessment of size reduction as apreliminary step in the production of ethanol from lignocellulosic wastes. Biology Wastes, 30, 153-157, 1989.

CANETTIERI, E. V. Obtenção dos parâmetros e estudo cinético da hidrólise ácida dos resíduos florestais de eucalipto. Tese de Doutorado, Faculdade de Engenharia do Campus de Guaratinguetá, Universidade Estadual Paulista, SP, 145, 2004.

CANILHA, L.; MILAGRES, A. M. F.; SILVA, S. S.; SILVA, J. B. A. E.; FELIPE, M. G. A.; ROCHA G. J. M.; FERRAZ, A. E.; CARVALHO, W. Sacarificação da biomassa lignocelulósica através de pré-hidrólise ácida seguida por hidrólise enzimática: uma estratégia de "desconstrução" da fibra vegetal. São Paulo, Rev. Analytica, 44, 2010.

CAO, G.-L.; REN, N.-Q.; WANG, A.-J.; GUO, W.Q., XU, J.-F., LIU, B.-F. Effect of lignocellulose-derived inhibitors on growth and hydrogen production by Thermoanaerobacterium thermosaccharolyticum W16. Int. J. Hydrogen Energ., 35, 24, 13475-13480, 2010.

CARVALHEIRO, F.; DUARTE, L. C.; GÍRIO, F. M. Hemicellulose biorefineries: a review on biomass pretreatments. Journal of Scientific \& Industrial Research, 67, 849-864, 2008.

CHANAKYA, H.N., VENKATSUBRAMANIYAM, R., MODAK, J. Fermentation and methanogenic characteristics of leafy biomass feedstocks in a solid phase biogas fermentor. Bioresour. Technol. 62, 71-78, 1997.

CHANDRA, R.; BURA, R.; MABEE, W.; BERLIN, A.; PAN, X.; SADDLER, J. Substrate Pretreatment: 
The Key to Effective Enzymatic Hydrolysis of Lignocellulosics? Biofuels, 67 - 93, 2007.

CHANG, V. S.; NAGWANI, M; HOLTZAPPLE, M. T. Lime pretreatment of crop residues bagasse and wheat straw. App. Biochem. Biotechnol., $74,1998$.

CHERNICHARO, C. A. de L. Reatores anaeróbios. Belo Horizonte. Em: Princípios de Tratamento Biológico de Águas Residuárias. UFMG, 5246, 2007.

DEUBLEIN, D.; STEINHAUSER, A. Biogas from Waste and Renewable Resources. An Introduction. Wiley - VCH, 2008.

DÍAZ, M. J.; CARA, C., RUIZ, E., ROMERO, I.; MOYA, M., CASTRO, E. Hydrothermal pre-treatment of rapeseed straw. Bioresour. Technol., 101, 2428-2435, 2010.

DOMÍNGUEZ, J. M. O. Efecto de los Productos de degradación originados en la explosión por vapor de biomasa de chopo sobre Kluyveromyces marxianus. Tese de doutorado. Universidad Complutense de Madrid. Facultad de Ciencias Biológicas. Departamento de Microbiología III. Madrid. 160, 2003.

DUFF, S. J. B.; MURRAY, W. D. Bioconversion of forest products industry waste cellulosics to fuel ethanol: A review. Elsevier Science ISSN : 0960-8524. Source Bioresour. Technol., 55, 1 , 1-33, 1996.

FAN, L.T.; LEE, Y.; BEARDMORE, D.H. Mechanism of the enzymatic hydrolysis of cellulose: Effects of major structural features of cellulose on enzymatic hydrolysis. Biotechnol. Bioeng., 22, 177-199, 1980.

FERNANDES, T. V.; KLAASSE BOS, G. J.; ZEEMAN, G.; SANDERS, J. P. M.; VAN LIER, J. B. Effects of thermo-chemical pre-treatment on anaerobic biodegradability and hydrolysis of lignocellulosic biomass. Bioresour. Technol., 100, 2575-2579, 2009.

FERNANDES, T. V. Hydrolysis inhibition of complex biowaste. Thesis, Wageningen University, Wageningen, NL, 176, 2010.

FENGEL, D., WEGENER, G. Wood: Chemistry, Ultrastructure, Reactions. De Gruyter, Berlin. 1984.
FURLAN JR., J. Dendê: Manejo e Uso dos Subprodutos e dos Resíduos. Embrapa Amazônia Oriental (Documentos 246), Belém, PA, Brasil, 2006.

GALLERT, C.; WINTER, J. Bacterial metabolism in wastewater treatment systems. In: Winter, J., Jördening, H. (Eds.), Environ. Biotechnol., 488, 2005.

GÁMEZ, S.; GONZÁLEZ-CABRIALES, J. J.; RAMÍREZ, J. A.; GARROTE, G.; VÁZQUEZ, M. Study of the hydrolysis of sugar cane bagasse using phosphoric acid. J. Food Eng., 74, 78-88, 2006.

HENDRIKS, A. T. W. M.; ZEEMAN, G. Pretreatments to enhance the digestibility of lignocellulosic biomass. Bioresour. Technol., 100, 10-18, 2009

HERRERA, A.; TÉLLEZ-LUIS S. J., RAMÍREZ, J. A., VÁZQUEZ, M. Production of Xylose from Sorghum Straw Using Hydrochloric Acid. J. Cereal Sci., 37, 2003.

HERRERA, A.; TÉLLEZ-LUIS S. J., GONZÁLEZ-CABRIALES, J. J., RAMÍREZ, J. A., VÁZQUEZ M. Effect of the hydrochloric acid concentration on the hydrolysis of sorghum straw at atmospheric pressure. J. Food Eng., 63, 103-109, 2004 .

HU, ZH.; YU, HQ. Application of rumen microorganisms for enhanced anaerobic fermentation of corn stover. Proc. Biochem., 40, 2371-2377, 2005.

INSAM, H.; FRANKE - WHITTLE, I.; GOBERNA, M. Microbes in Aerobic and Anaerobic Waste Treatment. in: H. Insam, I. Franke - Whittle, M. Goberna (Eds.), Microbes at Work. From Waste to Resources. Springer, 1 - 34, 2010.

KIIPPER, P. G. Estudo da pré-hidrólise ácida do bagaço de cana-de-açúcar e fermentação alcoólica do mosto de xilose por Pachysolen tannophilus. Dissertação (mestrado) - Universidade Estadual Paulista, Instituto de Biociências de Rio Claro, 100, 2009.

LASER, M.; SCHULMAN, D.; ALLEN, S. G.; LICHWA, J.; ANTAL, M. J., JR.; LYND, L. R. A comparison of liquid hot water and steam pretreatments of sugar cane bagasse for bioconversion to ethanol. Bioresour. Technol., 81, 33-44, 2002. 
LAVARACK, B. P.; GRIFFIN, G. J.; RODMAN, D. The acid hydrolysis of sugarcane bagasse hemicellulose to produce xylose, arabinose, glucose and other products. Biomass and Bioenergy, 23, 367-380, 2002.

LESCHINE, S. B. Cellulose degradation in anaerobic environments. Review of Microbiology, 49, 399-426, 1995.

LYND, L. R.; WEIMER, P. J.; VAN ZYL, H.; PRETORIUS, I. S. Microbial cellulose utilization: fundamentals and biotechnology. Microbiology and Molecular Biology Reviews, 66, 50677, 2002.

MILLER,G.L. Use of dinitrosalicylic acid reagent for determination of reducing sugars. Anal. Chem., 31, 426-428, 1995.

MOLDES, A. B.; CRUZ, J. M.; DOMÍNGUEZ, J. M.; PARAJÓ, J. C. Production of a cellulosic substrate susceptible to enzymatic hydrolysis from pre hydrolyzed barley husks, Agric. Food Sci. Finland, 11, 51-58, 2002.

MOSIER, N.; WYMAN, C.; DALE, B.; ELANDER, R.; LEE, Y.Y.; HOLTZAPPLE, M.; LADISCH, M. Features of promising technologies for pretreatment of lignocellulosic biomass. Bioresour. Technol., 96, 673-686, 2005.

MSHANDETE, A.; BJORNSSON, L.; KIVAISI, A. K.; RUBINDAMAYUGI M.S.T.; MATTIASSON B. Effect of particle size on biogas yield from sisal fibre waste. Renewable Energy, 31, 23852392, 2006.

MURPHY, J.D., MCCARTHY K. "Ethanol Production from Energy Crops and Wastes for Use as a Transport Fuel in Ireland". App. Energy, 82, 148-66, 2005.

NIZAMI, A-S; KORRES, N. E.; MURPHY, J. D. Review of the Integrated Process for the Production of Grass Biomethane. Environ. Sci. Technol., 43, 22, 8496-8508, 2009.

PABÓN-PEREIRA, C. P. Anaerobic digestion in sustainable biomass chains. Ph.D. thesis, Wageningen University, Wageningen, The Netherlands, 2009.

PALMQVIST, E.; HAHN-HÄGERDAL, B. Fermentation of lignocellulosic hydrolysates. II: inhibitors and mechanisms of inhibition. Bioresour. Technolo., 74, 25-33, 2000.
PAVLOSTATHIS , S. G.; GIRALDO-GOMEZ, E. Kinetics of Anaerobic Treatment. Water Sci. Technol., 24, 8, 35-59, 1991.

PEDERSEN, M.; MEYER, ANNE S. Lignocellulose pretreatment severity-relating $\mathrm{pH}$ to biomatrix opening: REVIEW. New Biotechnol., 27, 6, 2010.

PETERSEN M. O., LARSEN J., THOMSEN M. H. Optimization of hydrothermal pretreatment of wheat straw for production of bioethanol at low water consumption without addition of chemicals. Biomass and Bioenergy, 33, 5, 834840, 2009.

OGEDA, T. L.; PETRI, D. F. S. Hidrólise enzimática de biomassa. Química Nova, 33, 7, 15491558, 2010.

OH, K.-K., KIM, S.-W., JEONG, Y.-S., HONG, S.-I. Bioconversion of cellulose into ethanol by nonisothermal simultaneous saccharification and fermentation. Appl. Biochem. Biotechnol., 89, 15-30, 2000.

OLIVEIRA, F. M. V. 2010. Avaliação de diferentes pré-tratamentos e deslignificação alcalina na sacarificação da celulose de palha de cana. Dissertação Mestrado - Programa de Pós-Graduação em Biotecnologia Industrial na Área de Conversão de Biomassa - Escola de Engenharia de Lorena da Universidade de São Paulo. Lorena, São Paulo, 98.

RABELO, S. C. Avaliação de desempenho do pré-tratamento com peróxido de hidrogênio alcalino para a hidrólise enzimática de bagaço de cana-de-açúcar. Dissertação de mestrado. Universidade Estadual de Campinas. Campinas, SP: [s.n.], 2007.

RAMOS, L. P. The chemistry involved in the steam treatment of lignocellulosic materials. Química Nova, 26, 6, 863-871, 2003.

RODRÍGUEZ-CHONG, A.; RAMÍREZ, J.A.; GARROTE, G.; VÁZQUEZ, M. Hydrolysis of sugarcane bagasse using nitric acid: a kinetic assessment. J. Food Eng.61, 143-152, 2004.

ROSSELL, C. E. V. Fermentação do hidrolisado. III Workshop Tecnológico sobre Hidrólise para Produção de Etanol. Campinas, SP. Disponível em: <http://www.inovacao.rei.unicamp. br/etanol/report/Hidrolise\%20Rossel\%20 
Fermenta\%E7\%E3o\%20do\%20Hidrolisado. pdf> Acesso em: 20/08/2011, 2006.

RUIZ, E., CARA C.; MANZANARES, P.; BALLESTEROS, M.; CASTRO, E. Evaluation of steam explosion pre-treatment for enzymatic hydrolysis of sunflower stalks. Enzyme and Microbial Technology, 42, 160-166, 2008.

SAHA, B.C.; COTTA, M.A. Ethanol production from alkaline peroxide pretreated enzymatic all y saccharified wheat straw. Biotechnol. Progress, 22, 449-453, 2006.

SÁNCHEZ, G.; PILCHER, L.; ROSLANDER, C.; MODIG, T.; GALBE, M.; LIDEN, G. Dilute-acid hydrolysis for fermentation of the Bolivian straw material Paja Brava. Bioresour. Technol., 93, 3, 249-56, 2004.

SARROUH, B. F.; JOVER, J.; GONZÁLEZ, E. Estudio de la hidrólisis del bagazo con ácido sulfúrico concentrado utilizando dos variantes de una sola etapa y una sola etapa modificada para la obtencion de etanol y análisis técnico-econômico de dicho proceso. Rev. Ingenieria e Investigación, 25, 3, 34-38, 2005.

SHARMA, P.; AGRAWAL, D. P.; KOTLIA, B. S.; GUPTA, S. K.; BRISLEY, J. Environmental magnetism of lake sedimentation in Kumaon Himalayas: Indian Natl Sci Acad Proc, 54 A, 4, 595-6604, 1988.

SILVA, M. G.; SILVA JR.,F.G. Produção de Polpa Celulósica a partir de Línter de Algodão. Disponível em: https://uspdigital.usp.br/siicusp/ cdOnlineTrabalhoVisualizarResumo?numero InscricaoTrabalho $=3335 \&$ numeroEdicao $=14$. Acesso em: 21/01/2012, 2006.

SILVERSTEIN, R. A.; CHEN, Y.; SHARMA-SHIVAPPA, R. R.; BOYETTE, M. D.; OSBORNE, J. A comparison of chemical pretreatment methods for improving saccharification of cotton stalks. Bioresour. Technol., 98, 3000-3011, 2007.

SIVERS, M.V., ZACCHI, G. A techno-economical comparison of three processes for the production of ethanol from pine. Bioresour. Technol. 51, 43-52, 1995.

SOUZA, O.; FEDERIZZI, M., COELHO, B., WAGNER, T. M.; WISBECK, E. Biodegradação de resíduos lignocelulósicos gerados na bananicultura e sua valorização para a produção de biogás. Rev. Brasileira de Eng. Agrícola e Ambiental, 14, 4, 438-443, 2010.

SUN, J.X., SUN, X.F., ZHAO, H., SUN, R.C. Isolation and characterization of cellulose from sugarcane bagasse. Polym. Degrad. Stab. 84, 331-339, 2004.

SUN, Y.; CHENG, J. Hydrolisis of lignocellulosic materials for ethanol production: a review. Bioresour. Technol., 83, 1-11, 2002.

TAMANINI, C.; HAULY, M. C. O. Resíduos agroindustriais para produção biotecnológica de xilitol. Semana: Ciências Agrárias, Londrina, 25, 4, 315-330, 2004.

TAHERZADEH, M. J.; KARIMI, K. Pretreatment of Lignocellulosic Wastes to Improve Ethanol and Biogas Production: A Review. Int. J. Molecular Sci., 1422-0067, 2008.

VÁZQUEZ, D.; LAGE, M. A.; PARAJÓ, J. C.; ALONSO J. L. Empiricalassessment on the cellulase digestibility of processed Eucalyptuswood. App. Biochem. Biotechnol., 37, 123-139, 1992.

VÁZQUEZ, M., OLIVA, M., TÉLLEZ-LUIS, S. J., RAMÍREZ, J. A. Hydrolysis of sorghum straw using phosphoric acid: evaluation of furfural production. Bioresour. Technol., 98, 30533060, 2007.

WYMAN, C. E. Ethanol production from lignocellulosic biomass: review. In: Wyman, C.E. (Ed.), Handbook on Bioethanol, Production and Utilization. Taylor \& Francis, Washington, DC (Chapter 1), 1996.

XIAO , Z:; ZHANG, X.; GREGG, D. J.; SADDLER, J. $N$. Effects of sugar inhibition on cellulases and $\beta$-glucosidase during enzymatic hydrolysis of softwood substrates. App. Biochem. Biotechnol., 115, 1-3, 2004.

ZABIHI, S.; ALINIA, R.; ESMAEILZADEH, F.; KALAJAHI, J. F. Pretreatment of wheat straw using steam, steam/acetic acid and steam/ ethanol and its enzymatic hydrolysis for sugar production. Biosystems engineering, 105, 288-297, 2010.

ZHANG, Y.H.P.; LYND, L.R. Toward an aggregated understanding of enzymatic hydrolysis of cellulose: noncomplexed cellulase systems. Biotechnol. Bioeng. 88, 7, 797824, 2004. 